\title{
REFLEXIONES SOBRE LOS CONCEPTOS DE INTOLERANCIA, TOLERANCIA Y LIBERTAD
}

ELIA NATHAN BRAvo

INSTITUTO DE INVESTIGACIONES FILOSÓFICAS Universidad Nacional Autónoma de MÉxico

En la literatura filosófica reciente ha comenzado a discutirse de nuevo el tema de la tolerancia, sobre todo con referencia a las etnias, minorías, etc. En el pasado también fue periódicamente discutido, en forma muy notable, y por primera vez se discutió a principios de la época moderna, en relación con la coexistencia de una diversidad de grupos religiosos ([6], p. 143). Así, parecería que el tema de la tolerancia surge cuando hay un cambio de percepción acerca de la bondad o maldad de ciertas prácticas, formas de vida o culturas.

Un aspecto importante de estas discusiones es que en general hay poca claridad acerca de lo que significa el concepto de tolerancia y los conceptos asociados de intolerancia y libertad. Dada esta situación, en este ensayo ofreceré unas definiciones de estos conceptos y trataré de justificarlas.

Dicha justificación consiste en destacar básicamente dos cuestiones. a) Dichas definiciones son compatibles con algunos de los usos que tienen estos conceptos en el lenguaje ordinario y en la literatura relevante; aunque no son compatibles con todos los usos, ya que éstos son contradictorios. b) Estas definiciones son útiles para clasificar o conceptualizar ciertos fenómenos sociales. Más concretamente, para ilustrar la diferencia entre regímenes intolerantes y tolerantes, me referiré a fenómenos históricos, y para mostrar la utilidad de tener definiciones distintas de los conceptos de tolerancia y libertad, mencionaré algunos fenómenos sociales contemporáneos. Como puede verse por esta segunda línea de justificación, el propósito de este ensayo es, en el fondo, ofrecer un análisis conceptual y empírico de los fenómenos a los que - a veces en forma confusa - aluden estos términos, más que sostener que sólo se utilizan estos términos en el sentido definido.

En esta sección ofreceremos las definiciones antes aludidas y haremos explícitos algunos aspectos implícitos en ellas. 
Un sistema social (esto es, una sociedad o una institución) es intolerante cuando está constituido de tal forma que tiene una disposición tal que sistemáticamente excluye la posibilidad de que exista una diversidad de formas de vida o prácticas o culturas; o sea cuando tiene la disposición de perseguir la pluralidad, buscando la uniformidad mediante la coerción ([12], p. 244).

Hay un uso en el lenguaje ordinario del término "tolerancia" en el que éste significa soportar algo malo o erróneo, por ejemplo "Juan tolera el dolor". Tomando en cuenta este uso, podemos definir un sistema social como tolerante cuando permite que exista, a veces con restricciones, una pluralidad dada, pero se la considera como un mal necesario, como algo no respetable o valorable ([6], p. 143; [9], p. 112). Un aspecto fundamental de los regímenes de tolerancia es que, en la medida en que la existencia de los grupos tolerados es vista no como si estuviera fundada en un derecho sino en una concesión por parte de las autoridades, esta concesión es revocable en cualquier momento, esto es, en cualquier momento se puede pasar a la persecución ([13], p. 240).

Finalmente, con respecto a los regímenes de libertad, podemos decir que éstos se dan en un sistema social cuando en él se acepta la existencia irrestricta de una pluralidad de grupos diferentes sobre la base de que todos ellos tienen derecho a existir y son valorados positivamente, respetados, o por lo menos considerados con indiferencia.

De acuerdo con estas definiciones, los conceptos antónimos son los de intolerancia y libertad. En cambio, tolerancia se refiere a una situación intermedia, en tanto que comparte con el fenómeno de intolerancia la misma actitud de rechazo a la diversidad, pero difiere en relación con los grupos y actividades que se permiten; y, por otra parte, comparte con el fenómeno de libertad el que se permita (al menos parcialmente) la existencia de grupos o actividades plurales, pero difiere de un régimen de libertad con respecto a la valoración de dichos grupos $\mathrm{o}$ actividades. $\mathrm{O}$ sea, la tolerancia se refiere al fenómeno en que la conducta que se tiene en relación con ciertos grupos o prácticas, por parte de la autoridad que se cataloga de tolerante, no coincide con sus valores y creencias respecto de esos grupos o prácticas.

Ahora bien, las definiciones que hemos ofrecido son muy abstractas, lo cual nos ha permitido ser breves y hablar de lo esencial; empero, su carácter abstracto hace que resulten difíciles de aplicar a situaciones concretas. Con el fin de hacer aplicables estas definiciones, desarrollaré ahora una serie de aspectos implícitos en ellas. Estas definiciones se refieren al fenómeno complejo disposición-conducta: en los casos de la intolerancia y de la libertad, se habla de la conducta o acción de perseguir, o dejar existir, a ciertos grupos, y también de las razones que motivan dicha conducta, y que son la valoración positiva o negativa de dichos grupos, fundada en cier- 
tas creencias, valores y/o proyectos sociales. En la definición de tolerancia también se alude al fenómeno complejo disposición-acción, pero en este caso la acción, que es la de permitir la existencia de ciertos grupos, no está motivada por la disposición del sistema social que permite su existencia, o sea, no está ocasionada por el conjunto de creencias y valores o por el proyecto social del sistema, sino que está motivada por cuestiones externas o accidentales, como pueden ser las del alto costo social o económico, que significaría eliminar al grupo cuya existencia es mal vista.

¿Por qué definir estos conceptos en términos del fenómeno complejo disposición-acción? Es claro que si no lo hiciésemos así sólo contaríamos con dos conceptos, el de intolerancia, como sinónimo de persecución, y el de libertad, como sinónimo de no persecución; empero, como espero demostrar en este ensayo, es útil para comprender ciertos fenómenos sociales el contar con tres términos. Además, para los análisis históricos o sociológicos es importante tomar en cuenta no sólo las acciones sociales sino también los motivos o razones tras ellas, si es que se quiere comprender cabalmente los fenómenos históricos o sociales. Pero como esta razón es demasiado general y abstracta, pasemos a ilustrar con el concepto de intolerancia por qué debemos definirlo en términos del fenómeno complejo disposición-acción.

En la definición ofrecida sostuvimos que en un régimen de intolerancia la disposición es la de no aceptación de la pluralidad, y la acción o conducta es la de perseguir a los grupos alternativos. Por "persecución" entenderé los castigos violentos que las sociedades históricamente han utilizado para tratar de eliminar la existencia de los grupos alternativos, entre los cuales se incluye la cancelación de derechos - como hacer contratos de compraventa, testar, y otros-, encarcelamiento, exilio, privación de la vida, etc. Así definida la persecución, considero, al igual que San Agustín ([3], Ep. 185 , II, 11, p. 456) y otros autores ([12], p. 242), que no toda persecución es criticable: por ejemplo, a mi juicio, perseguir asesinos es legítimo. En verdad, es importante recordar que toda sociedad que históricamente ha existido, ha perseguido, ya que, para que exista un orden social dado, es necesario que se exijan ciertas conductas y se prohíban otras vía castigos. Hasta aquí hemos hablado de la conducta de perseguir, hablemos ahora de los motivos o razones por los cuales se persigue. Obviamente puede haber una multitud de razones por las que una sociedad persigue: por defensa propia, por impedir que se viole una legalidad dada, por conseguir la unidad mediante de la uniformidad, etc. En caso de que las razones por las que se persigue nos parezcan legítimas, hablaremos de una persecución justa, pero si nos parecen ilegítimas, diremos que la persecución es injusta. El término "intolerancia" se refiere a un subgrupo de las razones ilegítimas para perseguir: se refiere a la razón o motivo consistente en no aceptar la 
pluralidad. Otras razones ilegítimas que pueden motivar una persecución injusta son, por ejemplo, la búsqueda de poder político, la búsqueda de beneficios económicos, etc.; en estos casos no hablaríamos de intolerancia, ya que la razón no es la de suprimir la pluralidad.

Si por "intolerancia" entendemos un subgrupo de razones ilegítimas que motivan las persecuciones injustas, entonces el término "intolerancia" tendrá una carga valorativa negativa: decir de un sistema social que es intolerante, es criticarlo o rechazarlo. Así, por ejemplo, si decimos de la Edad Media que fue una época de intolerancia religiosa, por una parte, la describimos como un periodo en que ocurría la persecución sistemática de los grupos religiosos alternativos al oficial precisamente por su carácter de ser alternativos y, por otra parte, también expresamos nuestro rechazo ante dicho estado de cosas. Ahora bien, tanto en el lenguaje ordinario como en algunos textos especializados encontramos que a veces el término "intolerancia" no tiene una carga valorativa negativa, sino positiva o neutral; en este ensayo lo utilizaré con su sentido negativo, ya que, como espero demostrar más adelante (pp. 91-93), es lo más conveniente.

Para resumir, hemos visto hasta aquí que el concepto de intolerancia se refiere al fenómeno complejo consistente en llevar a cabo una persecución sistemática por la razón de querer suprimir toda forma de vida o cultura alternativa a la oficial; pero además de referirse a una situación empírica, este concepto sirve también para expresar una valoración negativa o crítica del fenómeno al que se refiere. Cabe destacar que, si bien en la definición que hemos dado de intolerancia este término se refiere al fenómeno complejo disposición-conducta, también puede utilizarse para referirse tan sólo a la disposición, o razón, o motivo, dado que éste puede existir sin que exista el otro elemento de la conducta, o sea sin que exista la persecución. En este caso, "intolerancia" significa que en el ámbito de los valores o de los proyectos sociales no se reconoce la legitimidad de una pluralidad de formas de vida, o de grupos. En este ensayo aparecerá uno u otro sentido de "intolerancia", según lo requiera la cuestión tratada.

Tratemos ahora de precisar más la relación entre persecución e intolerancia examinando otros puntos de vista que se oponen al aquí vertido.

Algunos autores (por ejemplo, Kamen más adelante) parecen identificar los conceptos de persecución e intolerancia. Por mi parte, considero que. dicha identificación no es correcta, ya que lleva a que el concepto de intolerancia pierda su contenido empírico específico. En efecto, si identificamos intolerancia con persecución, resultaría que toda época ha sido intolerante, ya que en toda época ha existido la persecución, por ser ésta esencial para mantener el orden o legalidad existente; pero si puede decirse de cualquier sistema social o época que es intolerante, entonces este término pierde 
su contenido empírico específico de referirse a un estado de cosas en que impera la uniformidad gracias a la coerción.

Así pues, persecución e intolerancia se refieren a cuestiones distintas; empero, ¿están necesariamente correlacionados? Kallen parece considerar que éste es el caso, ya que sostiene que la persecución consiste en la intolerancia activa y aplicada, y que los sentimientos básicos tras la persecución son la intolerancia y el miedo ([10], p. 83). O sea, Kallen parece considerar que toda persecución está fundada en la intolerancia. Pienso que ésta es una idea incorrecta ya que, por tener el término "intolerancia" un sentido valorativo negativo, dicha idea implica que toda persecución es una conducta injusta, mala o rechazable. Empero, creer esto es olvidar que toda sociedad persigue o coacciona a aquellos que violan el orden social existente, y es también olvidar que deberían poderse dar razones para justificar que un caso particular de persecución es condenable, dado que no todas las persecuciones son condenables, y no meramente utilizar un término con carga valorativa negativa como puede ser el de "intolerancia". Creo que estas consideraciones establecen que no toda persecución es consecuencia de la intolerancia, sino que puede haber otros motivos (legítimos o no) para perseguir. Por otra parte, la relación inversa también ocurre: no toda intolerancia lleva a la persecución, como sucede, por ejemplo, en los regímenes "tolerantes". Si se aceptan estas dos últimas tesis, se sigue que "intolerancia" (referido a una ideología o proyecto social) y "persecución" se refieren a fenómenos diferentes que no están relacionados necesariamente, sino que pueden presentarse uno sin el otro.

Otra concepción diferente a la que exponemos aquí es la de James Fitzjames Stephen (en la versión de Cranston, [6], p. 145), para quien la intolerancia es necesaria para preservar cualquier sociedad, en la medida en que tanto una legalidad dada, como una moral dada, requieren de castigos o persecuciones para garantizar su cumplimiento. Destacaré dos ideas que aquí aparecen. a) Todo sistema legal o moral requiere de castigos o persecuciones que garanticen su cumplimiento, idea que hemos sostenido antes. b) Al igual que Kallen, Stephen considera que toda persecución se funda en la intolerancia, pero a diferencia de Kallen, considera que, como la persecución es una conducta deseable porque permite la supervivencia de un orden social dado, la intolerancia es también algo deseable. Pienso que el uso del término "intolerancia" en este contexto no es correcto porque violenta su uso ordinario típico, en el cual este término tiene un sentido valorativo negativo; como dice Cranston ([6], p. 143), más afortunado sería el uso de algún término tal como "orden", "disciplina", "autoridad", "control". Además, y más importante aún, considero que es fundamental conservar el sentido negativo que tiene "intolerancia", aunado a un contenido em- 
pírico específico - como es el de no aceptar la existencia de la diversidad o pluralidad-, ya que es precisamente este concepto el que nos abre la posibilidad de pensar que ciertos regímenes, órdenes sociales o sistemas legales o morales no son deseables en tanto que son sistemas que no permiten la existencia de la diversidad o pluralidad. Así pues, se puede aceptar con Stephen que todo sistema social requiere perseguir para garantizar la existencia de un orden o legalidad dada, pero de esto no se sigue que cualquier persecución llevada a cabo dentro del orden o legalidad establecida sea correcta, ya que hay órdenes o legalidades no deseables, como son los órdenes sociales intolerantes, o los totalitarios, y cuyas persecuciones son por tanto injustas, aunque sean legales o lícitas dentro de dicho orden. Puesto en otros términos, a diferencia de Stephen, pienso que es importante contar con un término que tenga una carga valorativa negativa porque, si aceptamos que hay persecuciones justas e injustas, la única forma de distinguir entre éstas no es en términos de conducta, ya que persecución es la misma en ambos casos, sino en términos de los motivos que dan lugar a ella, y como "intolerancia" se refiere (parcial o totalmente) a los motivos y en el lenguaje ordinario tiene generalmente un sentido negativo, entonces conviene usar este término con carga valorativa negativa.

Tratemos de aclarar más por qué conviene conservar el sentido valorativo negativo que típicamente tiene el concepto de intolerancia en el lenguaje ordinario. Pienso que si uno quiere hacer análisis históricos o sociológicos conviene contar con un término que indica rechazo al fenómeno que se estudia, con el fin de evitar el problema usual de que la explicación que uno da se convierta en una justificación del fenómeno explicado. Daré dos ejemplos. El primero es sociológico y lo ofrece la teoría funcionalista, la cual, por no contar con términos valorativos negativos, al explicar por qué, por ejemplo, es funcional la existencia de reglas o leyes, y consecuentemente, por qué son funcionales los castigos o persecuciones, acaba por justificar como algo valioso cualquier legalidad o a cualquier persecución. El otro ejemplo es histórico: uno puede querer explicar por qué la herejía fue perseguida en el Medievo y encontrar que dicha persecución fue una actividad que se realizó en virtud del sistema de valores y proyectos sociales que animaban la Iglesia y el Estado en aquel entonces, y además uno puede encontrar que dicho sistema de valores y proyecto social es perfectamente racional y coherente. En este caso, para que la explicación de este fenómeno de persecución no dé como resultado una justificación de dicho fenómeno, se puede apelar al concepto de intolerancia, con el cual se querría decir que, a pesar de estar respaldada la persecución a los herejes por la legalidad existente en el Medievo, o sea, por los valores y proyectos sociales existentes entonces, sin embargo, dicha persecución fue injusta por estar fundada en una legalidad 
intolerante que no aceptaba la pluralidad religiosa. Cabe destacar que el concepto de intolerancia no se refiere a un conjunto de valores y proyectos sociales ni a una legalidad que sea incoherente o irracional -en verdad, las ideologías intolerantes que justifican la persecución de algún grupo son, casi siempre, perfectamente coherentes y racionales - sino que remite a un conjunto de valores o proyectos sociales que, desde nuestro punto de vista, o sea, desde otro sistema valorativo, no resulta legítimo o valioso. Por ello, para que el cargo de intolerancia realmente pueda sostenerse, es necesario ofrecer razones específicas de por qué la pluralidad particular que rechaza el régimen o época catalogada de intolerante es en verdad una pluralidad deseable o valiosa. En fin, me parece conveniente contar con el término de intolerancia como un término con carga valorativa negativa cuando se hacen análisis históricos, ya que dicho concepto saca a luz que, aunque una persecución se realice en virtud de una legalidad dada, esto no hace que la persecución sea justa, ni el hecho de que una ideología o conjunto de valores o proyecto social que motiva una persecución sea racional y coherente implica que sea una ideología aceptable o deseable; en pocas palabras, el concepto de intolerancia nos permite explicar un fenómeno sin por ello justificarlo. Dejemos aquí el problema del sentido valorativo del concepto de intolerancia, que en última instancia no es lo más importante, y regresemos al asunto central del contenido empírico de este concepto.

Una manera de precisar aún más el significado empírico del concepto de intolerancia es compararlo con el de tolerancia. Pienso que el rasgo fundamental que diferencia a un régimen intolerante de uno tolerante es que en el primero la persecución es sistemática, mientras que en el segundo la persecución es esporádica, o bien, no existente. Aclaremos. En un régimen intolerante la persecución es sistemática y violenta, y tiene por fin eliminar la existencia de los grupos alternativos al oficial; dicha persecusión está generada por una ideología o un proyecto social bien articulado en el que la existencia de grupos que encarnan formas de vida o prácticas o culturas alternativas se percibe como una amenaza o un impedimento para realizar la ideología o el proyecto en cuestión, y por lo cual se busca eliminar la existencia de dichos grupos. Ahora bien, es precisamente porque se trata de una persecución sistemática por lo que hemos sostenido anteriormente que en los regímenes intolerantes la razón que genera la persecución es una disposición, actitud o conformación particular, es decir, no es por causas aleatorias que se persigue, sino porque el conjunto de creencias y valores, o el proyecto social, que lo definen como ese sistema social particular es tal que necesariamente va a perseguir. En cambio, en un régimen de tolerancia pueden darse dos situaciones distintas. Una consiste en que el sistema social tiene una ideología o proyecto intolerante, pero no persigue porque las 
circunstancias no se lo permiten - tal es, por ejemplo, el caso de la Iglesia católica después del siglo XVII. La otra situación de tolerancia consiste en que hay persecución, pero ésta es de un tipo diferente a la persecución fundada en la intolerancia, ya que es una persecución violenta no sistemática, sino ocasional y local, y/o una "persecución" no violenta. Ejemplos de "persecuciones" no violentas son multar a los grupos alternativos, impedirles llevar a cabo ciertas prácticas, aislarlos geográficamente, o cualquiera de las otras formas de opresión que Goffman describe magistralmente con el rubro de "estigmatización" ([8]); el objetivo de este tipo de "persecución" no violenta es el de limitar -y no el de eliminar- la existencia de los grupos alternativos. En esta segunda situación, las razones para la persecución pueden ser o bien el que un sistema social tenga una ideología o proyecto intolerante pero no cuenta con los medios necesarios para perseguir, o bien una serie de ideas no totalmente articuladas acerca de la maldad o indeseabilidad de los grupos tolerados, y que funcionan como justificación (y no como "causa") en caso de que motivos o "causas" aleatorias generen la necesidad de una persecución violenta. Un ejemplo de este segundo tipo de régimen de tolerancia es el que vivieron los judíos durante la Edad Media, como veremos posteriormente.

Cabría preguntarse por qué en el concepto de tolerancia hemos incluido tres casos diferentes, a saber, de no persecución, de persecución violenta no sistemática y de "persecución" no violenta, asociados ya sea a una ideología intolerante -en que los grupos alternativos aparecen como una amenaza para la existencia del sistema social que tiene dicha ideología-, o a una serie de ideas no articuladas que presentan a los grupos alternativos o tolerados como indeseables aunque no necesariamente como amenazantes. La razón es que los regímenes de tolerancia son básicamente inestables, ya que consisten en regímenes en que no se acepta que tengan derecho a existir los grupos alternativos pero que en la práctica no los pueden eliminar, y por lo cual son las condiciones materiales existentes en un momento dado las que determinan qué tantas limitaciones se le imponen a la existencia de dichos grupos, esto es, qué tipo de persecución, si es que alguna se les aplica.

En síntesis, hemos sostenido que el concepto de intolerancia debe entenderse como un concepto que se refiere a un régimen en que un sistema social persigue de manera violenta y sistemática los grupos alternativos al oficial, debido a que dicho sistema cuenta con una ideología o proyecto social en que la existencia de una pluralidad de grupos alternativos es percibida como indeseable, y más aún como amenazante para la existencia de dicho sistema social, o sea, porque cuenta con una ideología o proyecto que requiere de la uniformidad para poder llevarse a cabo. Además, cuando nosotros aplicamos el concepto de intolerancia a un sistema social, no sólo lo describimos 
como de cierto tipo, sino que también expresamos una valoración negativa respecto a dicho sistema. Por otra parte, el concepto de tolerancia se refiere a un régimen en que si bien el sistema social cuenta con una ideología o proyecto intolerante, $\mathrm{o}$ al menos, con una serie de ideas sueltas acerca de la indeseabilidad de ciertos grupos, en la práctica se permite su existencia, generalmente con limitaciones.

\section{II}

En esta sección ofreceremos la justificación para las definiciones de intolerancia y tolerancia que ofrecemos en la sección anterior. Esta justificación se subdivide en dos partes. En la primera trataremos de mostrar que dichas definiciones recuperan algunos usos que tienen estos términos en el lenguaje ordinario, sobre todo con referencia a individuos, ya que es como típicamente se usan estos términos. En la segunda parte trataremos de mostrar, mediante el examen de algunos casos concretos de persecuciones religiosas, que estos conceptos, tal y como los hemos definido, son útiles para conceptuar o entender ciertos fenómenos históricos.

Veamos primero cómo ciertos usos de estos conceptos en el lenguaje ordinario son retomados por las definiciones que dimos de ellos en la sección I.

En el lenguaje ordinario, decimos de una persona que es intolerante cuando sólo reconoce como bueno o aceptable en los otros un solo tipo de conducta, o sea, cuando no es capaz de respetar en los otros conductas diferentes a las que él cree realizar; así, intolerante es quien, siendo monógamo, no puede aceptar que otros sean polígamos, o que siendo católico, no puede reconocer que otros tengan derecho a pertenecer a religiones distintas. Es importante notar que "intolerante" se aplica a quien exhibe la conducta de rechazo de manera sistemática, y no tan sólo en alguna ocasión; así, por ejemplo, intolerante no es el que rechaza a una persona homosexual específica, sino a cualquier homosexual. Y es precisamente porque se trata de una conducta sistemática de rechazo, por lo que se considera que la persona que exhibe esta conducta tiene una actitud, disposición o carácter intolerante. Para el sentido común, la actitud o disposición intolerante puede estar basada en la arrogancia -creer que sólo uno mismo tiene la verdad, o tiene acceso a lo valioso- o en la cerrazón mental, el no poder captar la racionalidad o el sentido o el valor que tienen formas de vida diversas a la propia ([6], p. 143). Así pues, el contenido empírico del concepto de intolerancia, referido a personas individuales, es el ser individuos que tienen una actitud o disposición tal que sistemáticamente rechazan en las otras conductas diferentes a las suyas, o sea, sólo reconocen como legítimo un tipo de conducta específico. El concepto de intolerancia, referido a individuos, también tiene un sentido valorativo negativo: catalogar a alguien 
de intolerante es rechazarlo, es considerar que sus actitudes y conductas no son deseables. Esta valoración negativa, por supuesto, implica un juicio valorativo de nuestra parte. Así, por ejemplo, podríamos decir de un empresario que rehúsa contratar homosexuales, que es intolerante, en caso de que nosotros consideremos que la homosexualidad es permisible, o por lo menos que consideremos que no es pertinente para la función que desempeñaría el trabajador; pero no diríamos que dicho empresario es intolerante porque se rehúsa a contratar ladrones, ya que no consideramos que el ser ladrón sea una actitud ni lícita, ni funcional para el empresario. O sea, no toda conducta de rechazo a formas de vida o conductas es intolerante, sino sólo lo es cuando juzgamos que la forma de vida o conducta rechazada es, desde nuestro punto de vista, legítima o permisible. Así, es sólo desde un punto de vista dado, desde un sistema valorativo específico, que cierta actitud y conducta resulta intolerante. Vemos así que en el lenguaje ordinario aparecen las notas distintivas que mencionamos en la definición de intolerancia, a saber: 1) la intolerancia consiste en el rechazo o persecución de prácticas alternativas a la propia o a la oficial; 2) pero no todo rechazo constituye un caso de intolerancia, sino sólo el rechazo de prácticas que nosotros, los que emitimos el juicio de intolerancia, consideramos permisibles; 3) por ende el concepto de intolerancia tiene una carga valorativa negativa; 4) el rechazo de las prácticas, formas de vida o culturas debe ser sistemático; 5) por ser un rechazo sistemático, se considera que dicha conducta o acción está ocasionada por una diposición o ideología intolerante.

Con respecto al concepto de tolerancia, en el lenguaje ordinario encontramos muchos casos en que éste significa un mal necesario, un tener que soportar algo indeseable porque no se puede combatirlo, y que es el sentido que hemos recuperado en la definición de tolerancia antes ofrecida. Ejemplos en el uso ordinario son los siguientes: "Juan tolera el dolor", "La entrada es a las 9:00 a.m., pero se conceden 10 minutos de tolerancia", "Pedro hace un gran esfuerzo por tolerar a los niños", "Los intolerantes deberían ser tolerados", etcétera.

Pasemos ahora a la segunda parte de la justificación. Dado que nuestro propósito es mostrar que los conceptos de intolerancia y tolerancia, tal y como los definimos, son útiles para realizar análisis históricos del fenómeno de persecución, examinaremos varios casos de persecuciones religiosas (violentas y no violentas) con el fin de averiguar si hay algunos casos de persecución religiosa que puedan clasificarse como casos de intolerancia religiosa, otros como casos de tolerancia religiosa y finalmente otros como casos de persecuciones religiosas ocasionales motivadas por causas aleatorias. 
Antes de pasar a los ejemplos, conviene notar que el término "persecución religiosa" es ambiguo, ya que puede querer decir "persecución a grupos religiosos", o bien, "persecución motivada por razones religiosas"; el contexto determinará en qué sentido se utiliza el término, aunque en este ensayo generalmente utilizaremos el segundo sentido. Pasemos ahora a los ejemplos.

Los historiadores contemporáneos generalmente consideran que la cultura romana, al igual que la mayoría de las culturas antiguas, no fue una cultura que tuviera una actitud de intolerancia religiosa, a pesar de que llevó a cabo algunas persecuciones de grupos religiosos. La razón por la cual no hablan de intolerancia religiosa es que durante el Imperio Romano las persecuciones fueron ocasionales y locales, alternando con largos periodos de paz, y que dichas persecuciones estuvieron motivadas por razones políticas y no religiosas. Así, por ejemplo, la quema romana del segundo templo de Jerusalén en $70 \mathrm{~d}$.C. se ha considerado como motivada políticamente, en tanto refleja el deseo de las autoridades romanas de suprimir la rebelión política existente en Palestina, y no el deseo de suprimir la fe judía ([5], p. 248). Igualmente, los historiadores consideran que la persecución romana de los cristianos no se debió a razones religiosas, o sea, no estuvo motivada por el deseo de suprimir la religión cristiana por considerarla una falsa religión. En efecto, dado que para los romanos los ritos religiosos paganos tenían básicamente el sentido civil o político de rendir culto a las autoridades romanas, la no participación de los cristianos en estos ritos fue percibida como un acto de deslealtad política, lo cual motivó su persecución ([9], p. 113; [13], p. 240). Hemos visto así dos casos de persecuciones a grupos religiosos no ocasionadas por motivos religiosos y por lo cual no podemos decir que fueron generadas por una posición de intolerancia religiosa por parte del Imperio Romano.

Veamos ahora algunos ejemplos de persecuciones religiosas motivadas por razones religiosas. Generalmente los historiadores consideran que en la Edad Media los judíos fueron tolerados (p. ej. [5], p. 248). Así, por una parte, a pesar de considerarse que tenían una religión errónea, su práctica religiosa fue soportada dentro de ciertos límites (p. ej. a veces fueron aislados geográficamente, a veces se les prohibió realizar su culto religioso, etc.), por necesidades prácticas (dificultad en eliminar a toda una comunidad, importancia económica de ésta, etc.). Por otra parte, los judíos fueron perseguidos violentamente en algunas ocasiones. Así, por ejemplo, durante la primera cruzada, los judíos fueron perseguidos a instancias no del papa sino de ciertos sectores populares que participaban en la cruzada y debido al estado de fervor religioso que generó el proyecto cruzado de eliminar a los infieles ([5], p. 249). Éste ciertamente es un ejemplo de persecución motivada por razones religiosas. Sin embargo, conviene destacar que durante 
la Edad Media también hubo otras persecuciones violentas a judíos que no estuvieron motivadas - por lo menos totalmente- por razones religiosas. Así por ejemplo, en los siglos XIII y XIV en algunas regiones de Europa el clima de descontento social originó la persecución a los judíos -en este caso los judíos fueron tomados como chivos expiatorios por pensarse que ellos eran los causantes de la peste negra, o de los males económicos existentes. Dados estos dos ejemplos, ¿podríamos afirmar que la Edad Media fue una época de intolerancia hacia los judíos? Pienso que no, por varias razones.

En primera lugar, hay que notar que la persecución violenta de los judíos no fue sistemática durante la Edad Media, sino que fue ocasional y local, lo cual sugiere que no hubo un único motivo tras dichas persecuciones, el cual pudiésemos catalogar con el rubro de "intolerancia". En verdad, hemos visto que hubo motivos, a veces, de fervor religioso, y otras veces, sociales, tras la persecución de los judíos.

En segundo lugar, consideremos las razones para la persecución. Podemos aceptar la idea de Chazan ([5], p. 250) de que, a pesar de que hubo distintos motivos tras la persecución violenta medieval de los judíos, como telón de fondo estuvieron siempre presentes ciertos estereotipos del judío como ser maligno y agresivo —estereotipo generado parcialmente por el papel fundamental que desempeñaron los judíos en de la crucifixión de Cristo ([5], p. 248). Sin embargo, creo que esta consideración no implica que podamos afirmar que la Edad Media fue una época de intolerancia religiosa contra los judíos. En efecto, para poder hablar de intolerancia religiosa, de rechazo a la pluralidad religiosa, se requiere la existencia de una institución o sistema social que tenga un sistema de creencias religiosas bien desarrollado y que implique el rechazo de la pluralidad religiosa, y por lo cual pueda considerarse que es dicho sistema de creencias, y no otra "causa", lo que genera la persecución (sistemática) de los grupos religiosos. Esto ciertamente no existió en la Iglesia católica, así, por ejemplo, Santo Tomás, a tono con su época, sostuvo que debían perseguirse a los herejes, pero no a los judíos ni a los infieles ([9], p. 114). Por ello, no podemos afirmar que la Iglesia católica medieval fue intolerante con los judíos. Por otra parte, es cierto que en el imaginario popular medieval existieron estereotipos negativos del judío (como ideología difusa) que contribuyeron parcialmente a la persecución, parcialmente, porque fueron los motivos sociales de crisis económica o social, o de fervor religioso, los que detonaron la persecución, mientras que dichos estereotipos más bien operaron como elementos de racionalización o justificación de la persecución. Por consiguiente, debemos considerar que la Edad Media fue una época de tolerancia religiosa, o sea, una época en que existió una serie de creencias no bien articuladas 
acerca de la maldad de los judíos, pero éstos no fueron sistemáticamente perseguidos en forma violenta.

En tercer lugar, pienso que el hecho de que los judíos fueron "perseguidos" de forma no violenta durante la Edad Media tampoco nos permite hablar de una época de intolerancia religiosa. En efecto, dicha "persecución" no violenta no fue sistemática: no siempre fueron aislados geográficamente, etc. Además, el propósito de dicha "persecución" no violenta fue limitar la existencia de los judíos y no eliminar su existencia, objetivo que sí está presente en los regímenes de intolerancia. Es por estas dos razones que la "persecución" no violenta a los judíos debe conceptuarse como un caso de tolerancia y no de intolerancia.

Examinemos ahora un caso de persecución religiosa motivada por la intolerancia religiosa. En la Edad Media, y sobre todo a partir del siglo XI, la persecución de los herejes o heterodoxos, esto es, a los cristianos que no eran católicos, fue sistemática; tanto así, que se creó en el siglo XII un organismo especialmente diseñado para llevar a cabo esta persecución: la Inquisición. Pero no sólo la persecución de los herejes fue sistemática, sino que las razones para llevar a cabo esta persecución fueron religiosas y, más aún, parte intrínseca de la Iglesia católica, por lo cual podemos afirmar que la Iglesia católica medieval fue una institución intolerante para con la heterodoxia. Para conocer cuáles fueron estas razones, lo mejor es que recordemos ciertas tesis de San Agustín, el gran ideólogo de la persecución religiosa.

Para San Agustín, a diferencia de otros, como los donatistas, el proyecto de la iglesia cristiana debía consistir en ser católico o universal, es decir, debía expanderse por todo el orbe, ya que así está profetizado en las sagradas escrituras. Para lograr este proyecto católico de que la Iglesia católica fuese la única iglesia existente en todo el orbe, se debían utilizar cualesquiera medios, incluso el de perseguir a las personas para obligarlas a entrar a la Iglesia católica ([3], Ep. 173, 10, p. 380). Esto es, con el fin de mantener la unidad de la Iglesia católica se debía perseguir a los herejes. Es importante destacar que el proyecto católico que San Agustín diseñó es bastante ambicioso, pues se trataba no sólo de que la Iglesia católica fuese universal, sino más aún, de que fuese la institución dominante de la sociedad, o sea, se trataba de crear una sociedad cristiana dedicada en todos sus subsistemas o instituciones a servir a Dios. Por ello, San Agustín planteó que los reyes "deben someterse a Cristo", para que por medio de sus leyes y castigos difundan la religión cristiana, identificada con la Iglesia católica, y se genere así una sociedad al servicio de Dios ([3], Ep. 185, V, 19, p. 465; [3], Ep. 155, II, 7, p. 195; [1], Unit. Ecc. 22, p. 685). Dadas estas ideas de San Agustín, que contribuyó en buena medida a crear la Iglesia católica medieval, resulta claro que el 
proyecto católico fue un proyecto de dominación religiosa, y en función de lo cual la Iglesia católica medieval se dedicó a perseguir sistemáticamente a los herejes, a los cristianos que disentían con la Iglesia católica.

Hemos hablado del proyecto institucional-religioso por el que San Agustín luchó exitosamente. Veamos ahora la justificación religiosa que San Agustín ofreció para la persecución. Este padre de la iglesia sostuvo, a tono con la concepción monoteísta del cristianismo, que sólo el cristianismo es la religión verdadera, y por lo cual sólo dentro de la Iglesia católica —que a diferencia de las otras iglesias cristianas, como la Iglesia donatista, la Iglesia pelagiana, etc., representa realmente a Cristo- podría encontrarse la salvación ([1], Unit. Ecc. 2, p. 651). Pero como para San Agustín, el principio de caridad cristiana implica la idea paternalista de que se debe ayudar a las personas a salvarse, es necesario perseguir a los herejes, coaccionarlos a entrar a la Iglesia católica ([3], Ep. 185, I, 2, p. 448; [1], Unit. Ecc. 55, p. 759). Cabe destacar que para San Agustín el objetivo tras la persecución de los herejes no es tanto que meramente se vuelvan miembros de la Iglesia católica (lo cual podría dar lugar a falsos conversos), sino el que, con castigos, venzan sus costumbres, su indolencia o su arrogancia, y escuchen sin prejuicios la doctrina católica, que por ser tan evidentemente la verdadera, será aceptada ([2], Ep. 93, V, 16, p. 613).

En la medida en que la persecución sistemática de los herejes por parte de la Iglesia católica estuvo fundada tanto en la doctrina católica de la no salvación fuera de la iglesia, junto con una concepción paternalista de la caridad, como en el proyecto institucional católico de dominación; podemos afirmar que la persecución de los herejes fue ocasionada por la posición de intolerancia religiosa de la Iglesia católica medieval. Hablamos de intolerancia porque las razones religiosas para perseguir herejes son razones claramente intolerantes, excluyentes de la diversidad religiosa. En efecto, la doctrina exclusivista de la no salvación fuera de la Iglesia católica y la doctrina paternalista de la caridad como deber de ayudar a los otros a salvarse a cualquier costa, son doctrinas que excluyen la legitimidad de cualquier otra vía religiosa que no sea la católica. Por lo que respecta al proyecto católico de dominación, podemos decir que éste es igualmente intolerante, ya que, por definición, excluye la posibilidad de una pluralidad de iglesias y religiones distintas. Cabe destacar que esta tesis de que la Iglesia católica medieval fue intolerante se ajusta con la definición formal de intolerancia que ofrecimos antes. En efecto, hemos tratado de mostrar que la Iglesia católica medieval estuvo conformada de tal forma, o sea, como católica -i.e., con una doctrina exclusivista y paternalista, y un proyecto de dominación- que tuvo que perseguir sistemáticamente todo intento de diversidad cristiana. 
Sostuvimos antes que el término "intolerancia" tiene un sentido valorativo negativo; es en este sentido que hemos afirmado que la Iglesia católica medieval fue intolerante. Las razones por las que la persecución de los herejes es errónea o ilegítima no las expondremos aquí, ya que podemos encontrarlas en Locke, Spinoza, Bayle y Mill.

Hemos afirmado que la Iglesia católica medieval fue intolerante. Sin embargo, hay que matizar esta afirmación, ya que ninguna persona, institución o sistema intolerante lo es en todos los sentidos. Así, por ejemplo, si bien la Iglesia católica fue intolerante con los herejes, fue tolerante con los judíos; igualmente, dicha iglesia manifestó una fuerte dosis de intolerancia religiosa, pero fue bastante tolerante con la conducta moral de sus miembros, esto es, tuvo estándares morales laxos, lo cual fue una de las causas de varios movimientos heréticos, como los de los donatistas y los pelagianos, en el siglo IV d.C., y los cátaros y valdenses en el siglo XII, etc. Finalmente, la intolerancia puede tener límites, sobre todo en instituciones que aspiran a sobrevivir por largo tiempo. Tal fue el caso de la Iglesia católica medieval, que si bien persiguió a los herejes, también fue capaz de asimilar a su institución, con la aceptación de las órdenes de dominicos y franciscanos, ciertos planteamientos "heréticos" para los que había una gran demanda social, y que eran los de la predicación y la pobreza voluntaria.

Para terminar esta sección examinaré dos propuestas que difieren de la que aquí he sostenido respecto a las causas o motivos por los cuales la Iglesia católica medieval persiguió sistemáticamente a los heterodoxos cristianos; a saber, la Iglesia persiguió a los herejes por estar definida con base en un proyecto intolerante, el "católico". La primera es la de Kamen, para quien: "La base de la intolerancia (religiosa) en la Edad Media fue la alianza entre la Iglesia y el Estado" ([11], p. 16). Cierto es que en la Edad Media (como en la Antigüedad), fue el Estado el que persiguió a los grupos religiosos por solicitud de la Iglesia católica, y esto porque la Iglesia carecía de los medios coercitivos para perseguir por sí misma (además de tener una doctrina que se lo prohibía). Igualmente es verdad que en la época moderna, al separarse Iglesia y Estado, pudieron existir sociedades con una pluralidad religiosa. Sin embargo, Kamen yerra al considerar como causa o motivo lo que es tan sólo un medio; en efecto, la alianza Iglesia-Estado fue el medio o condición de posibilidad para que la Iglesia persiguiera (por medio del Estado), pero la Iglesia no persiguió porque estuviera aliada con el Estado (recuérdese que el término "intolerancia" se refiere a las causas o motivos de la persecución). Por ello, la tesis de Kamen sería correcta si fuese la siguiente: "La base de la persecución en la Edad Media fue la alianza Iglesia-Estado." Tal vez la razón por la cual Kamen considera verdadera la tesis antes citada es que identifica persecución con intolerancia, pero hemos argumentado 
antes que tal identificación no es correcta porque "persecución" remite a una conducta, mientras que "intolerancia" se refiere a uno de sus posibles motivos o causas. Además, la identificación de persecución con intolerancia en el contexto de la temática que trata Kamen me parece que da lugar a una idea errónea: la Iglesia católica dejó de ser intolerante a partir de la época moderna, en la que se dio la separación Iglesia-Estado, dado que la fuente de la intolerancia era la alianza entre estos dos poderes. Es un hecho que desde el siglo XVIII la Iglesia católica ha dejado de perseguir a los otros grupos religiosos, pero esto no significa que haya dejado de ser intolerante en el plano doctrinal. En efecto, para dicha iglesia, en el nivel doctrinal no se puede aceptar más que al catolicismo como la única religión verdadera, aunque en la práctica no se deben perseguir a las personas, sino los errores que cometen ([6], p. 145; [13], p. 239). Dicha intolerancia ideológica no sólo es parte de la doctrina oficial de la Iglesia católica sino que también la encontramos entre los fieles de la iglesia; así, por ejemplo, aún hoy día en México, a pesar de que ha transcurrido más de un siglo después de la Reforma juarista, la tercera parte de los mexicanos piensan que sólo debería aceptarse la religión católica ([4], p. 4). Esta intolerancia religiosa ha desempenado un papel importante en la expulsión de las sectas protestantes en las comunidades indígenas de Chiapas, o sea, es una intolerancia que puede dar lugar a castigos violentos, o no violentos (como campañas de difamación). Por ello, la mejor manera de comprender la posición de la Iglesia católica a partir de la época moderna es clasificándola como una iglesia tolerante, o sea, una iglesia con una ideología intolerante pero que no persigue de modo violento y sistemático porque, al romperse su alianza con el Estado, dejó de tener los medios con que hacerlo. Si esto es correcto, entonces, a diferencia de Kamen, y otros autores ([4], pp. 3, 7,9 ), debemos referir el concepto de intolerancia a la ideología y proyecto social de la institución, como los elementos que son la causa o motivo de la persecución, y no definirlo en términos de las relaciones entre Iglesia y Estado como ellos sugieren.

La segunda propuesta que examinaré consiste en la tesis de que la intolerancia del catolicismo, o de otras religiones, radica en su carácter monoteísta ([14], p. 599), o bien radica en la tesis de que fuera de la iglesia no hay salvación ([7], p. 255). Ciertamente, para una primera aproximación al tema de la intolerancia religiosa, estas tesis son iluminadoras. Cierto es también que consideradas en abstracto tanto la concepción monoteísta como la de que fuera de la iglesia no hay salvación son creencias intolerantes. Empero, varía mucho cómo son entendidas éstas por las personas en un lugar y momentos específicos. Así, por ejemplo, los judíos, a pesar de su monoteísmo, llevaron a cabo muy pocas persecuciones; los primeros cristianos, a pesar 
de su concepción exclusivista de la salvación, se opusieron a la persecución religiosa, etc. Por ello, pienso que para encontrar los elementos doctrinales o institucionales que dan lugar a la intolerancia en sentido fuerte (que incluye el elemento de persecución) han de tomarse en cuenta muchos factores - si la religión en cuestión tiene pretensiones universalistas o no, si pone énfasis o no en la aceptación de una doctrina, si dicha doctrina está lo suficientemente especificada como para distinguir entre ortodoxia y heterodoxia, los varios elementos de la doctrina que conforman con claridad una actitud intolerante, la creencia en que la institución eclesial jerárquica es necesaria para que exista la religión, la presencia de algún proyecto de dominación, etc. (cfr. [13], p. 239).

En síntesis, para justificar las definiciones de intolerancia y tolerancia propuestas en la sección I hemos tratado de mostrar en esta sección que dichas definiciones retoman ciertos usos que tienen estos conceptos en el lenguaje ordinario. Por otra parte, hemos tratado de mostrar que estos conceptos, así definidos, son útiles para realizar análisis históricos, en la medida en que, al clasificar distintos tipos de persecuciones y sus causas, nos permiten conceptuar mejor los fenómenos de uniformidad y diversidad que están presentes aun en una época tan aparentemente monolítica como la Edad Media.

\section{III}

En la sección I sostuvimos que los conceptos de intolerancia y de libertad eran los conceptos antónimos, mientras que el concepto de tolerancia se refería a una situación intermedia, en la que si bien en la práctica no hay persecución violenta sistemática —o sea, hay un régimen práctico de libertad o semilibertad-, en el ámbito ideológico o en el proyecto social hay intolerancia. En esta última sección, y como forma de justificar la definición dada de libertad, quisiera mostrar por qué es importante, al menos para realizar análisis históricos o sociológicos, distinguir entre tolerancia y libertad. Cabe destacar que no siempre en la literatura, por ejemplo la de corte político, se distingue entre estos dos conceptos. Tenemos así el caso de Locke, que en su Carta de la tolerancia defiende generalmente, más que la tolerancia religiosa, la libertad religiosa, esto es, defiende la coexistencia de diversas iglesias sobre la base de que todas ellas tienen derecho a existir sin que el Estado intervenga en sus prácticas o en sus creencias, y sobre la base de que los individuos tienen derecho a tener las creencias religiosas que ellos consideren las apropiadas. Un ejemplo contemporáneo es el de Wolff, que sostiene que la tolerancia es la virtud de la democracia ([15], p. 4), o sea, que sostiene que es una condición necesaria para que exista la democracia, el que puedan existir libremente, y ser respetados, distintos 
grupos de interés. Sin embargo, y a diferencia de estos autores, yo pienso que es iluminador distinguir estos conceptos. Veamos.

Los historiadores se han preguntado por el origen del régimen de libertad religiosa que existe hoy día. Por dicho régimen se entiende la situación consistente en que los individuos son libres para escoger su credo religioso, las asociaciones religiosas tienen autonomía para determinar sus prácticas, y está establecido la igualdad legal de las diferentes confesiones frente al Estado ([13], pp. 239-40). Actualmente consideran que éstos regímenes tuvieron su origen en el régimen de tolerancia que se creó en el siglo XVII, en el que muchos Estados europeos terminaron por aceptar la existencia de varios grupos religiosos distintos con tal de evitar una guerra civil, y no en la doctrina protestante de la libertad de la conciencia individual ([15], p. 15) -en verdad, ésta no fue entendida por los varios grupos protestantes como una doctrina que implicara la libertad religiosa, ya que dichos grupos se dedicaron a perseguir, tanto como los católicos. En otras palabras, fue originalmente la tolerancia religiosa la que dio lugar a la libertad religiosa, y no una ideología en que se afirma la libertad religiosa. Así pues, históricamente es importante distinguir entre tolerancia y libertad religiosas porque han existido situaciones que no son ni de libertad ni de intolerancia, sino intermedias.

La situación de la Iglesia católica mexicana contemporánea (hasta 1991) nos ofrece un ejemplo interesante de los fenómenos de tolerancia y libertad. Vimos en la sección II que la intolerancia no se da en todos los sentidos, no es absoluta. Lo mismo sucede con la libertad. Por ejemplo, en México vivimos básicamente en un régimen de libertad religiosa, en el sentido antes definido de libertad religiosa. Sin embargo, esto no significa que la Iglesia católica (o cualquier otra) sea libre en todos los sentidos. En efecto, legalmente hablando, las iglesias no tienen derecho a participar políticamente (al menos en el sentido de que los religiosos tengan derecho a votar), no tienen derechos económicos (esto es, no pueden ser propietarias de bienes inmuebles), ni tampoco tienen derecho a impartir una educación religiosa en las escuelas; aunque muchas de estas restricciones legales no se ponen en práctica. Me parece que esta situación en que se encuentran las iglesias en México debe describirse como de tolerancia del Estado a la Iglesia. En efecto, el Estado es intolerante en el aspecto jurídico con relación a ciertas prácticas políticas, económicas y educativas que las iglesias podrian tener; pero en la práctica el Estado les concede la oportunidad de llevar a cabo algunas de las prácticas prohibidas. Por supuesto, la Iglesia católica expresa periódicamente su inconformidad con el hecho de que realice ciertas prácticas no como resultado de un derecho legal sino como consecuencia de una concesión gubernamental; el peligro con esta situación de tolerancia es 
evidente: en cualquier momento el Estado puede pasar a poner en vigor las leyes que restringen la actividad de la Iglesia. En sintesis, me parece que para poder conceptuar adecuadamente la complicada situación de las iglesias en México debemos utilizar los dos conceptos de libertad y tolerancia: en México hay un régimen de libertad religiosa (i.e. los individuos tienen derecho a escoger su credo religioso, las diferentes confesiones son iguales ante el Estado y la Iglesia tiene autonomía para determinar todas sus actividades puramente religiosas), pero un régimen de tolerancia política, económica y educativa con respecto a la Iglesia por parte del Estado.

Finalmente, para concluir quisiera argumentar cómo el contar con los dos conceptos distintos de tolerancia y libertad nos puede ayudar a entender ciertos aspectos de algunos movimientos sociales contemporáneos. En los sesenta hubo en los Estados Unidos un movimiento de reivindicación de la comunidad negra. Lo que esta comunidad buscaba era eliminar la persecución no violenta a la que estaban sujetos y que consistia, por ejemplo, en ser aislados en ghettos, en escuelas para negros, y por otra parte, en el tener vedado el acceso a puestos de alguna importancia. Parte de su lucha consistía en cambiar la percepción negativa, prejuicio o intolerancia que había respecto de ellos; por ello, una de sus más famosas consignas fue la de "black is beautiful", o sea, el ser negro es algo tan digno y respetable como el ser blanco. Puesto en otros términos, para entender el movimiento negro hay que reconocer que ellos percibían su situación real (que puede no coincidir con su situación legal) como de tolerancia, y por lo cual su lucha por la "libertad" se dio en dos frentes: por una parte, luchando por eliminar la persecución no violenta, y por otra parte, mediante una lucha ideológica que buscaba alterar la percepción negativa que había de los negros.

Algo similar ocurre con los movimientos de homosexuales. Su lucha es contra la situación de tolerancia en que de hecho viven, y que consiste no sólo en persecuciones violentas no sistemáticas (como son las razzias), sino también en las no violentas, entre las cuales la más insidiosa es la de que no pueden comportarse públicamente como tales: no pueden tener ciertos gestos, posiciones, tonos de voz, intereses, usar ciertas palabras y vestimentas, etc. ([8], pp. 121, 130, 145). Por ello, su lucha por la libertad sexual incluye no sólo una lucha por eliminar las persecuciones a las que puedan estar sujetos, sino también en alterar la percepción social negativa de la forma de vida homosexual para que ésta sea aceptada como algo respetable y digno.

En fin, pienso que esto puede generalizarse a muchos movimientos de "minorías", como los movimientos de mujeres, de drogadictos, de prostitutas, etc. Todos ellos se tornan comprensibles si uno los conceptúa como movimientos en contra de una situación de tolerancia y en pro de un régi- 
men de libertad. En cambio, si identificamos tolerancia con libertad, estos movimientos aparecen como carentes de sentido en la medida en que de hecho no hay una situación de intolerancia a la que se puedan oponer; esto es, si identificamos tolerancia con libertad se nos oculta que hay situaciones que no son de intolerancia pero que tampoco son las situaciones plenamente deseables de libertad, de respeto a la otredad, a lo minoritario, a lo marginal.

\section{IV}

Para concluir quisiera poner énfasis en que el propósito de este ensayo ha sido fundamentalmente aclarar una serie de aspectos conceptuales $y$ empíricos relativos a los fenómenos de intolerancia, tolerancia y libertad, más que argumentar que las definiciones aquí propuestas son las únicas legítimas. Demos tres ejemplos.

Alguien puede sostener que la persecución violenta que sufrieron los judíos en el siglo XIV es un caso de intolerancia. Esto me parecería correcto, siempre y cuando esta afirmación no lleve a pensar que las causas de dicha persecución fueron las mismas que las causas o motivos para la persecución de los herejes. Como hemos tratado de demostrar, la causa de dicha persecución de los judíos fue el estado de crisis que generó la peste negra, y no la existencia de una institución esencialmente intolerante, como en el caso de la persecución de los herejes. Este ejemplo aclara el que las definiciones que propusimos están diseñadas para hacer análisis macrohistóricos o macrosociológicos, y no para referirse a acontecimientos individuales considerados aisladamente.

El segundo ejemplo plantea el problema de la intolerancia contra los intolerantes. Se puede sostener que debemos ser intolerantes con los intolerantes, por ejemplo, con los nazis; aunque ésta es una manera confusa de decir las cosas, ya que se utiliza el mismo término para hablar de dos fenómenos distintos. En efecto, la persecución violenta y sistemática de los judíos por los nazis estuvo fundada en un proyecto de dominación que incluía una posición de intolerancia racial, mientras que la "intolerancia" para con los nazis estuvo fundada en el deseo legítimo de defender los regímenes democráticos. Por otra parte, hablar de intolerancia contra los intolerantes puede sonar un tanto incoherente. Pienso que en el fondo no lo es, ya que si uno distingue entre persecuciones justas e injustas y nota que en cualquier sistema social, aun en aquellos donde existe un régimen de libertad, tiene que haber límites a las actividades permisibles para que haya un orden, o sea, se da uno cuenta que no es posible un régimen de libertad absoluta, entonces puede afirmarse que en un régimen de libertad se persigue legítimamente a aquellos que lo ponen en peligro, como son los intolerantes. Así, se puede hablar sobre la intolerancia contra los intoleran- 
tes, siempre y cuando se asuma que se está utilizando el mismo término para referirse a dos situaciones distintas.

Por último, se puede defender un principio de tolerancia o caridad como sinónimo de un principio de libertad, siempre y cuando resulte claro que lo que se defiende es el derecho de los otros a una existencia tan irrestricta como la de las "mayorías", a una existencia plena y digna, y no tan sólo el concederles a los otros la oportunidad de existir, probablemente en forma limitada.

\section{BIBLIOGRAFÍA}

[1] Agustín, San, Obras de San Agustín, edición bilingüe, BAC, Madrid, 1948, t. IV. [2] — Obras de San Agustín, edición bilingüe, BAC, Madrid, 1958, t. VIII.

[3] — Obras de San Agustín, edición bilingüe, 2a. ed., BAC, Madrid, 1972, t. XIa.

[4] Blancarte, Roberto, "Fortalecimiento del México secular", Este País, no. 3, junio de 1991.

[5] Chazan, "Persecution: Jewish Experience", en Mircea Eliade (ed.), The Encyclopedia of Religion, Macmillan, Nueva York, 1987, vol. 11.

[6] Cranston, M., "Toleration", en Paul Edwards (ed.), Encyclopedia of Philosophy, The Macmillan Company and the Free Press, Nueva York, 1967, vol. 8.

[7] Frend, X.H.C., "Persecution: Christian Experience", en Mircea Eliade (ed.), The Encyclopedia of Religion, Macmillan, Nueva York, 1987, vol. 11.

[8] Goffman, E., Stigma, Notes on the Management of Spoiled Identity, Prentice Hall, Nueva Jersey, 1963.

[9] Labrousse, Elisabeth, "Religions Toleration", en Philip P. Weiner (ed.), Dictionary of the History of Ideas, Charles Scribner's Sons, Nueva York, 1973, vol. IV.

[10] Kallen, Horace M., "Persecution", en E.R.A. Seligman (ed.), Encyclopedia of the Social Sciences, Macmillan Co., Nueva York, 1948, vol. XII.

[11] Kamen, Henry, Nacimiento y desarrollo de la tolerancia en la Europa moderna, Alianza Editorial, Madrid, 1987.

[12] Otto, M.C., "Intolerance", en E.R.A. Seligman (ed.), Encyclopedia of the Social Sciences, Macmillan Co., Nueva York, 1948, vol. VII.

[13] Ruggiero, Guido de, "Religions Freedom", en E.R.A. Seligman (ed.), Encyclopedia of the Social Sciences, Macmillan Co., Nueva York, 1948, vol. XIII.

[14] Van Baaren, Theodorus P., "Monotheism", en Encyclopedia Britannica. Macropaedia, 15a. ed., Encyclopedia Britannica, Inc., Chicago, 1987, vol. 26.

[15] Wolff, Roberto Paul, "Beyond Tolerance", en R.P. Wolff, B. Moore, H. Marcuse (comps.), A Critique of Pure Tolerance, Beacon Press, Boston, 1969. 